\title{
Tour boats affect the activity patterns of bottlenose dolphins (Tursiops truncatus) in Bocas del Toro, Panama
}

\author{
Ayshah Kassamali-Fox ${ }^{\text {Corresp., } 1}$, Fredrik Christiansen ${ }^{2,3}$, Laura J May-Collado ${ }^{4,5,6}$, Eric A Ramos ${ }^{7,8}$, Beth A Kaplin ${ }^{9,10}$ \\ 1 Department of Environmental Studies, Antioch University New England, Keene, NH, USA \\ 2 Aarhus Institute of Advanced Studies, Aarhus C, Denmark \\ 3 Department of Bioscience, Zoophysiology, Aarhus University, Aarhus C, Denmark \\ 4 Department of Biology, University of Vermont, Burlington, VT, United States \\ ${ }^{5}$ Centro de Investigación en Ciencias del Mar y Limnología, Universidad de Costa Rica, San Jose, Costa Rica \\ 6 Tupper Balboa Ancon, Smithsonian Tropical Research Institute, Panamá, Republic of Panamá \\ 7 Department of Psychology, The Graduate Center, City University of New York, New York, New York, United States \\ 8 Fundación Internacional para la Naturaleza y la Sostenibilidad, Chetumal, Quintana Roo, United States of America \\ 9 Center of Excellence in Biodiversity and Natural Resource Management, University of Rwanda, Kigali, Rwanda \\ 10 School for the Environment, University of Massachusetts at Boston, Boston, Massachusetts, United States \\ Corresponding Author: Ayshah Kassamali-Fox \\ Email address: akassamali@antioch.edu
}

Bottlenose dolphins (Tursiops truncatus) of the Bocas del Toro archipelago are targeted by the largest boat-based cetacean watching operation in Panama. Tourism is concentrated in Dolphin Bay, home to a population of resident dolphins. Previous studies have shown that tour boats elicit short-term changes in dolphin behavior and communication; however, the relationship of these responses to the local population's biology and ecology is unclear. Studying the effects of tour boats on dolphin activity patterns and behavior can provide information about the biological significance of these responses. Here, we investigated the effects of tour boat activity on bottlenose dolphin activity patterns in Bocas del Toro, Panama over 10 weeks in 2014. Markov chain models were used to assess the effect of tour boats on dolphin behavioral transition probabilities in both control and impact scenarios. Effect of tour boat interactions was quantified by comparing transition probabilities of control and impact chains. Data were also used to construct dolphin activity budgets. Markov chain analysis revealed that in the presence of tour boats, dolphins were less likely to stay socializing and were more likely to begin traveling, and less likely to begin foraging while traveling. Additionally, activity budgets for foraging decreased and traveling increased as an effect of tour boat presence. These behavioral responses are likely to have energetic costs for individuals which may ultimately result in population-level impacts. Boat operator compliance with Panamanian whale watching regulations is urgently needed to minimize potential long-term impacts on this small, 
genetically distinct population and to ensure the future viability of the local tourism industry. 
1 Tour boats affect the activity patterns of bottlenose dolphins (Tursiops truncatus) in Bocas

2 del Toro, Panama

3

4 Ayshah Kassamali-Fox ${ }^{1}$, Fredrik Christiansen ${ }^{2,3}$ Laura Johanna May-Collado $^{4,5,6}$, Eric Angel

$5 \operatorname{Ramos}^{7,8}$, Beth Ann Kaplin 9,10

6

$7{ }^{1}$ Department of Environmental Studies, Antioch University New England, Keene, New

8 Hampshire, USA

$9 \quad{ }^{2}$ Aarhus Institute of Advanced Studies, Aarhus C, Denmark

$10{ }^{3}$ Department of Bioscience, Zoophysiology, Aarhus University, Aarhus C, Denmark

$11{ }^{4}$ Department of Biology, University of Vermont, Burlington, Vermont 05405, USA

$12{ }^{5}$ Centro de Investigación en Ciencias del Mar y Limnología, Universidad de Costa Rica, Costa

13 Rica

$14{ }^{6}$ Smithsonian Tropical Research Institute, Tupper Balboa Ancon, Panamá, Republic of Panamá

$15{ }^{7}$ Department of Psychology, The Graduate Center, City University of New York, New York, 16 New York, United States

$17{ }^{8}$ Fundación Internacional para la Naturaleza y la Sostenibilidad, Chetumal, Quintana Roo, 18 Mexico

$19{ }^{9}$ Center of Excellence in Biodiversity and Natural Resource Management, University of

20 Rwanda

$21{ }^{10}$ School for the Environment, University of Massachusetts at Boston, Boston, USA

22

23 Corresponding Author:

24 Ayshah Kassamali-Fox

2540 Avon St, Keene, New Hampshire 03431

26 Email address: akassamali@antioch.edu 
27 Abstract

28 Bottlenose dolphins (Tursiops truncatus) of the Bocas del Toro archipelago are targeted by the 29 largest boat-based cetacean watching operation in Panama. Tourism is concentrated in Dolphin 30 Bay, home to a population of resident dolphins. Previous studies have shown that tour boats 31 elicit short-term changes in dolphin behavior and communication; however, the relationship of these responses to the local population's biology and ecology is unclear. Studying the effects of tour boats on dolphin activity patterns and behavior can provide information about the biological significance of these responses. Here, we investigated the effects of tour boat activity on bottlenose dolphin activity patterns in Bocas del Toro, Panama over 10 weeks in 2014. Markov chain models were used to assess the effect of tour boats on dolphin behavioral transition probabilities in both control and impact scenarios. Effect of tour boat interactions was quantified by comparing transition probabilities of control and impact chains. Data were also used to construct dolphin activity budgets. Markov chain analysis revealed that in the presence of tour boats, dolphins were less likely to stay socializing and were more likely to begin traveling, and less likely to begin foraging while traveling. Additionally, activity budgets for foraging decreased and traveling increased as an effect of tour boat presence. These behavioral responses are likely to have energetic costs for individuals which may ultimately result in population-level impacts. Boat operator compliance with Panamanian whale-watching regulations is urgently needed to minimize potential long-term impacts on this small, genetically distinct population and to ensure the future viability of the local tourism industry. 
47

48

49

50

51

52

53

54

55

56

57

58

59

60

61

62

63

64

65

66

67

68

69

70

71

72

73

74

75

76

77

78

79

80

81

82

83

84

85

86

87

88

89

90

91

92

\section{Introduction}

Human-wildlife interactions are on the rise worldwide, generating widespread concern among conservation scientists about the effects of nonlethal human disturbance on the behavioral ecology and conservation status of affected wildlife populations (Duffus \& Dearden, 1990; Christiansen et al., 2015). In coastal regions, rising interest in the marine environment has led to an upsurge in boat-based cetacean watching tourism and assumptions about the sustainability of these activities has allowed for tourism operations to proliferate at an accelerated rate (O'Connor et al., 2009). The demand for cetacean watching is especially high in developing countries where regulatory frameworks for managing potential negative effects of tourism are often lacking (Christiansen et al., 2010; Mustika et al., 2013; Perez-Jorge et al., 2010). Understanding how tourism interactions impact wild cetaceans is vital for protecting threatened populations and ensuring the long-term sustainability of local boat-based tour businesses.

Unregulated tourism activities may impact animals through sublethal energetic effects, challenging the assumption of the sustainability of the industry (Pirotta \& Lusseau, 2015; Christiansen et al., 2015; Higham et al., 2015). A number of tourism impact studies have demonstrated an association between cetacean watching and short-term responses in cetaceans including changes in behavior (Lusseau, 2003; Pérez-Jorge et al., 2016), communication (MayCollado \& Quiñones-Lebrón, 2014; Heiler et al., 2016), respiration and dive characteristics (Stockin et al., 2008; Christiansen, Rasmussen, \& Lusseau, 2014), swim speed and directionality (Nowacek, Wells, \& Solow, 2001; Williams, Lusseau \& Hammond, 2006; Christiansen, Rasmussen \& Lusseau, 2014) and habitat use (Bejder, Dawson \& Harraway, 1999, Bejder et al., 2006b; Lusseau, 2005). It is often difficult to correlate short-term behavioral changes with longterm negative outcomes on the biology and ecology of targeted populations, however, there is growing evidence that repetitive short-term behavioral changes, induced by frequent disturbance, can influence life functions (i.e. feeding, predator response, migration and breeding) by imposing additional costs on the energetic budget of individuals (Christiansen, Rasmussen \& Lusseau, 2013; Senigaglia et al., 2016; Noren et al., 2016). Tour boat disturbance has been linked to shifts in the activity budgets of numerous cetacean species (Williams, Lusseau \& Hammond, 2006; Meissner et al., 2015; Pérez-Jorge et al., 2016; Tyne et al., 2018). These studies indicate that short-term avoidance tactics used by individuals can exert a cumulative effect on animals by altering activity budgets and potentially increasing energetic costs. On the individual level, the physiological constraints produced by lost foraging opportunities and increased traveling activity can lead to long-term negative effects on vital rates and reduced individual fitness. For example, tour boat interactions affected the diving and travelling behavior of female dolphins in Zanzibar, Tanzania (Stensland and Berggren, 2007) and was associated with increased female dive intervals in Fiordland, New Zealand (Lusseau, Slooten \& Currey, 2006). A 2016 meta-analyses comparing tour boat disturbance found that disruptions of activity budgets were one of the most consistent responses of cetaceans, further highlighting the use of activity budgets as a metric for evaluation of consequences of tour boat disturbance (Senigaglia et al., 2016).

Bottlenose dolphins (Tursiops spp.) are one of the most targeted small cetacean species for tourism due to their use of inshore habitats and limited movement patterns, making them easily accessible for tourism activities (Samuels et al., 2003). This species is currently listed by the global International Union for the Conservation of Nature (IUCN) as Least Concern (Wells, Natoli \& Braulik, 2019); however, the high geographic and genetic differentiation of the species makes it difficult to assess their actual vulnerability to anthropogenic pressures. In general, coastal populations often face multiple local threats to their conservation, including direct and 
93 indirect disturbance and harassment by high levels of boat traffic and commercial dolphin

94 watching activities, and may warrant a higher classification (Hawkins et al., 2017). For example,

95 a quantitative threat assessment concluded that the Fiordland bottlenose dolphin (Tursiops

96 truncatus) subpopulation qualifies as Critically Endangered based on the number of mature

97 individuals and the predicted rate of subpopulation decline over three generations (Currey et al.,

98 2009). Resident coastal dolphin communities are often genetically isolated with restricted home

99 ranges and are at increased risk for the cumulative effects of tourism as individual animals can be

100 subjected to repeated exposure to boat interactions over time (Pirotta et al., 2015). Furthermore,

101 individual animals may be forced to tolerate conditions of high disturbance if they are

102 physiologically or socially constrained to an area or if suitable alternative habitat is lacking (Frid

$103 \&$ Dill, 2002).

104 In Bocas del Toro, Panama, a small, genetically distinct population of coastal bottlenose

105

106

107 dolphins is the target of the largest dolphin-watching industry in Panama (e.g. May-Collado et al., 2019; Barragán-Barrera et al., 2017; Sitar et al., 2016). Preliminary analysis suggests the resident population ranges from 72 to 87 dolphins, with 37 individuals exhibiting a high residency rate (38.5 to 100\%) in the central dolphin-watching area known as Dolphin Bay (MayCollado et al., 2017). The dolphins use this embayment for a number of activities including foraging and socializing, and high sighting and recapture rates of females with dependent offspring also suggest it may serve as important nursery habitat for females with calves (MayCollado et al., 2019). Because many of these individuals are resident, they are exposed to tour boats year-round, placing them at increased risk for the cumulative effects of boat disturbance. Previous tourism impact studies at this site have shown that dolphins alter their diving and travelling behavior depending on the number and frequency of tour boat interactions (May-

116 Collado et al., 2015) and modify their acoustic structure (May-Collado \& Wartzok, 2008; May-

117 Collado \& Quiñones-Lebrón, 2014). In 2014, during a series of stakeholder forums held with the

118 local community, at least 12 companies, including cooperatives, tour operators and associations

119 were identified, and a fleet of over 165 boats possessing over 179 captains were estimated to be operating in the Bocas del Toro archipelago and offering dolphin watching tours at that time. It is very likely that the number of companies and boats have increased in the last 5 years. Since 2012, the International Whaling Commission (IWC) has publicly expressed concerns about the potential negative effects of high levels of unregulated boat-based tourism on bottlenose dolphins in Bocas del Toro $(I W C, 2019)$. In response to these concerns, the Panamanian government updated its official regulations to manage whale watching activities in the country (Resolución No. DM-0530-2017, Ministerio de Ambiente, República de Panamá, 2017). These regulations stipulate that boats should not approach dolphins closer than $100 \mathrm{~m}$ and whales closer than 250 $\mathrm{m}$, and that no more than two vessels should interact with one group of whales or dolphins at any one time. The government has also funded training efforts for boat operators to follow best practice guidelines for conducting boat-based dolphin tourism in Dolphin Bay. Despite these efforts, tour boat-dolphin interactions remain high due to lack of boat operator compliance and local government enforcement of tourism activities.

In this study, we assessed the impact of boat-based dolphin watching tourism on the behavioral patterns of bottlenose dolphins in Dolphin Bay, Bocas del Toro, Panama. We aimed to assess if tour boat interactions caused variations in the daytime activity budget of dolphins (hereafter referred to as 'activity budget') and whether these changes had the potential to affect dolphins through two vital mechanisms: lost energy acquisition (reduced foraging activity) and increased energy expenditure (increased travelling activity). We hypothesized that significant 
139 changes in individual energy gain and expenditure, if frequent enough, could potentially impact survival and reproduction and lead to long-term area avoidance and/or population decline if enough individuals are affected.

\section{Materials \& Methods Study area}

The Bocas del Toro Archipelago is located on Panama's northwestern Caribbean coast near the border of Costa Rica (Fig. 1). The central study area was defined as a $6.3 \times 3.1 \mathrm{~km}$ area called Bocatorito, also referred to locally as Dolphin Bay, due to the predictable presence of dolphins in the embayment (Fig. 1).

Dolphin Bay is characterized by shallow, clear waters approximately $20 \mathrm{~m}$ deep, possessing variable bottom substrate including mud, coral, sea grasses, and mangroves (Kaufmann \& Thompson, 2005). Because dolphins use this embayment year-round it is likely an important foraging habitat (May-Collado et al., 2017) where dolphins feed primarily on lowcalorie prey such as striped parrotfish (Scarus isiri) and dwarf round herring (Jenkinsia lamprotaenia) (Barragán-Barrera et al., 2019). Since monitoring efforts began in 2004, high sighting rates of mother-calf pairs (including two neonates observed in this study) suggest Dolphin Bay may also serve as critical habitat for females with dependent offspring. A recent study found that resident females possess a relatively long calving cycle ( $\sim 62$ months) and a high calf mortality rate (46\%) (May-Collado et al., 2019). Additionally, nuclear and mitochondrial DNA analyses indicate this population is isolated from others in the Caribbean, including the neighboring population of bottlenose dolphins in Costa Rica located $35 \mathrm{~km}$ away from the Bocas del Toro archipelago (Barragán-Barrera et al., 2017). Because the small dolphin community of Dolphin Bay shows such high site fidelity, they have become the main target for dolphin watching activities in the area, resulting in the largest dolphin watching fleet in Panama (MayCollado et al., 2012, 2015, 2019).

\section{Data collection}

The activity of bottlenose dolphins and tour boats was recorded in Dolphin Bay between July and September 2014 (Fig. 1). Surveys were conducted using a small research boat outfitted with a $10 \mathrm{~m}$ two stroke outboard engine. The research boat was launched from the dock of the Smithsonian Tropical Research Institute in Saigon Bay at 07:00, 4 to 5 days per week, and stayed out until 1300, weather permitting. We conducted non-systematic surveys of San Cristobal Bay en route to the central study area of Dolphin Bay, and then surveyed Dolphin Bay following a route which included the areas adjacent to the Bay (Fig. 1) until a group of dolphins was found. A group was defined as $>1$ dolphin moving in a similar direction and engaged in similar behaviors within five body lengths of each other (Mann, 1999).

In the presence of dolphins, the research boat was carefully operated to avoid rapid changes in speed and gear shifts, to minimize potential disturbance to dolphins. The speed of the boat was kept as low as possible to match the speed of the dolphins and to avoid cavitation noise. Additionally, dolphins were always approached from the side and rear. During follows, the boat was maintained in a parallel position to the focal dolphin group at a distance of $20 \mathrm{~m}$ or more, both in the presence and absence of tour boats (Nowacek, Wells \& Solow, 2001) throughout the data collection process. We could not control for the potential effect of the research boat on the behavior of dolphins, however, dolphin-watching boats in Dolphin Bay routinely approach dolphins at high speeds, at very close range $(<5 \mathrm{~m})$ and frequently shift gears, as well as engage 
185 in other aggressive tactics. Therefore, it was assumed that the measured effects of the tour boats

186 on the dolphins exceeded the possible effects from the research boat and was hence a

187 conservative measurement.

At the beginning of each dolphin encounter we recorded the time, the location (using a

\section{Behavioral sampling}

After having recorded the group information and environmental data, individual focal follows were conducted on a single dolphin associated with the focal group. Focal dolphins were selected primarily based on characteristic markings on the dorsal fin. Because the dorsal fin is the most visible and highly recognizable part of the dolphin, dorsal fin identification was used as the primary means of following the focal animal in most observations. However, if prominent scars, rake marks or skin disease were present on the peduncle of the animal and were reliably visible for each sampling period, these markings were also used for following the focal animal, often in combination with dorsal fin identification. Only adults with recognizable marks were selected as focal animals since the behavior of calves was not considered independent of their mothers.

Detailed behavioral information and associated data were collected for the focal animal (e.g. individual description, group size and distance to the nearest tour boat) every three minutes. At the beginning of each sample, one of four activity states was determined and recorded by focal-animal point sampling (Altmann, 1974). Activity states were defined to be mutually exclusive categories of behaviors that as a whole describe the entire activity budget of the focal dolphin. The different activity states for dolphin activity are defined in Table 1 (after Mann \& Smuts, 1999; Mann \& Sargeant, 2003) and are similar to ones used in other bottlenose dolphin impact assessment studies (e.g. Stensland \& Berggren, 2007; Stockin et al., 2008; Christiansen et al., 2010). If the focal animal was not sighted for a maximum of 4 minutes and the next recorded behavior was the same as that previously recorded, we assumed that the focal animal had been engaged in the same behavior during the missed sampling period. If the behavior had changed between successive recordings the behavior was assumed to have changed during the missed sampling period. Follows were terminated in the event of heavy precipitation and/or lightning, when sea state reached Beaufort 3, visibility deteriorated due to fog or rain, or when the focal animal was lost for $>6$ min. During surveys, if the same group of dolphins was resighted, we conducted a focal follow on a marked individual we had not yet followed that day. If this was not possible, we searched for another group of dolphins and selected a different individual in that group to conduct a focal follow.

Individual follows were classified as either control or impact scenarios. Follows conducted in the presence of the research boat only were treated as control sequences, while follows conducted with the research boat and one or more tour boats were classified as impact sequences. Interactions between tour boats and focal dolphins were defined as beginning when one or more tour boats were within $100 \mathrm{~m}$ of the focal dolphin and ended when the last tour boat exceeded this distance. This distance is consistent with the Panamanian government's whale watching codes of conduct regulations (Resolución No. DM-0530-2017).

This research was permitted by the Autoridad Nacional del Ambiente, República de Panamá, under permit no. SE/A-55-14, as well as permit no. SE/A 79-14 under Dr. L. J. May- 
231 Collado. The research was also approved by the IACUC committee of the Smithsonian Tropical

232 Research Institute, Panama (IACUC-STRI-2011-1125-201406).

233

234

235

236

237

238

239

240

241

242

243

244

245

246

247

248

249

250

251

252

253

254

255

256

257

258

259

260

261

262

263

264

265

266

267

268

269

270

271

272

273

274

275

\section{Data analysis \\ Markov chains}

We modeled the time-series of dolphin activity states obtained from the point sampling using time-discrete Markov chains (Guttorp \& Minin, 1995). We used a first-order Markov chain to assess the difference in transition from the preceding activity state to the immediately succeeding state in the presence (impact) and absence (control) of tour boats. The data obtained from the 3min focal animal point sampling intervals were first arranged into 2-way contingency tables of preceding activity state versus succeeding activity state (Lusseau, 2003). We developed two contingency tables: one for control and one for impact situations, depending on the presence of tour boats interacting with the focal dolphin between two behavioral samples. If no tour boat interaction occurred between two behavioral samples, the transition between these two samples was placed in a control table (no tour boats present, only research boat). If a tour boat interaction did occur between two samples, the transition was placed in an impact table (one or more tour boats present together with the research boat). When an impact chain followed a control chain, the first transition between them was discarded, as this chain could not be considered as either control or impact since it was not possible to determine the extent of the potential impact (Lusseau, 2003). To test the effect of tour boat presence on dolphin behavioral transitions, the impact and control contingency tables were compared using a Chi-square test. All analyses were completed in R v3.1.2. The R packages we used for the analyses were "markovchain" and "poLCA" (R Development Core Team, 2013).

\section{Behavioral transition probabilities}

To assess changes in dolphin activity states in the presence of one or more tour boats, transition probabilities from preceding to succeeding activity state were calculated for the control and interaction chains separately, following Lusseau (2003):

$$
p_{i j}=\frac{a_{i j}}{\Sigma_{j=1}^{n} a_{i j}}, \sum_{j=1}^{n} p_{i j}=1,
$$

where $i$ is the preceding activity state, $j$ is the succeeding activity state, $\mathrm{a}_{i j}$ is the number of transitions observed from activity state $i$ to $j$, and $\mathrm{p}_{i j}$ is the transition probability from $i$ to $j$ in the Markov chain and $n$ is the total number of activity states (i.e. 4). Each transition is the proportion of time a succeeding activity state was observed following a preceding activity state; therefore, we tested the effect of tour boat interactions by comparing the control and impact transition probability matrices for dolphin activity.

\section{Activity budgets}

The activity budget for control and impact situations was derived following Lusseau (2003). Differences between the control and impact activity budgets were tested using a Chi-square test, and each activity state in the control activity budget was compared to its corresponding activity state in the impact activity budget using a two-sample test for equality of proportions.

\section{Bout length}


276 The average bout length (the mean duration of time an animal remains in the same activity state) 277 of each activity state, $\mathrm{t}_{i i}$ was also calculated in the presence and absence of tour boats, following

278 Lusseau (2003):

279

280

281

282

283

284

285

286

287

288

289

290

291

292

293

294

295

296

297

298

299

300

301

302

303

304

305

306

307

308

309

310

311

312

313

314

315

316

317

318

$$
\overline{t_{i i}}=\frac{1}{1-p_{i i}}
$$

with a standard error of

$$
S E=\sqrt{\frac{p_{i i} \times\left(1-p_{i i}\right.}{n_{i}}}
$$

where $n_{i}$ is the number of samples with $i$ as preceding activity. The average bout length for each activity state in both chains was compared using a t-test.

\section{Recovery time}

To assess the recovery time, the expected number of transitions it took the dolphins to return to each activity state was approximated for both control and impact chains according to Stockin et al. (2008):

$$
E\left(T_{j}\right)=\frac{1}{\pi_{j}}
$$

where $\left(\mathrm{T}_{j}\right)$ denotes the time (i.e. number of transitions, i.e. $3 \mathrm{~min}$ ) it takes a dolphin to return to state $j$ given that the animal is currently in state $j$ and $\pi$ is the steady-state probability of each activity in the chain. The expected number of transitions was multiplied by the length of each transition unit $(3 \mathrm{~min}$ ) to calculate the average time $(\mathrm{min})$ it took the dolphins to return to each initial activity state. These average times were then compared between control and impact situations to assess the effect of tour boat interactions on dolphin activity states; higher values indicated a longer recovery time for dolphins to return to each initial activity state and lower values indicated a shorter recovery time.

\section{Results}

\section{Field effort}

During the 10-week study period, we collected a total of 74.9 hours of behavioral data from a maximum of 47 , and a minimum of 32 different focal dolphins, totaling 79 individual focal follows. Focal dolphins were followed for a minimum of $21 \mathrm{~min}$ ( 7 scans) and a maximum of 60 min (21 scans) under weather conditions which did not exceed Beaufort sea state 3. During this time period, 1,456 behavioral transitions were recorded, of which $829(57 \%)$ were classified as control and $627(43 \%)$ as impact. Control sequences lasted an average of 37 min (median $=36$; $\mathrm{SE}=3.0$; range $=3-96)$, and impact sequences averaged $36 \min ($ median $=32 ; \mathrm{SE}=3.6$; range $=$ $3-87)$. The number of boats interacting with focal dolphins at one time varied between 1 and 18 , with an average of 2 boats at a time ( $\mathrm{SE}=0.116)$. The majority of interactions between tour boats and dolphin groups involved one to two boats (55\%). In both control and impact situations, only a low number of transitions between resting and the other activity states were observed $(2 \%)$, which precluded the use of the resting activity state in the Markov chain analysis.

Peer] reviewing PDF | (2019:07:39800:1:1:ACCEPTED 17 Feb 2020) 
319 Therefore, any transitions involving resting were omitted and the Markov chain analysis

320 examined only the remaining three activity states (i.e. foraging, socializing and traveling, Table

321 1).

322

323

324

325

326

327

328

329

330

331

332

333

334

335

336

337

338

339

340

341

342

343

344

345

346

347

348

349

350

351

352

353

354

355

356

357

358

359

360

361

362

363

364

\section{Effect of tour boat interactions Behavioral transitions}

The results of the Markov chain analyses showed that tour boat interactions significantly affected dolphin activity patterns by altering the transitions between states (Chi-square test, $X^{2}=34.9251$; $\mathrm{df}=4 ; p<0.001)$. For all activity states, dolphins were more likely to remain in the same activity state (Fig. 2) than to change to another state (Fig. 2) between time samples. The effect of tour boats was not homogenous over all behavioral transitions. Overall, two behavioral transitions showed statistically significant differences $(p<0.05)$ between impact and control situations (Fig. 3). The probability of going from socializing to traveling $\left(X^{2}=4.2156, \mathrm{df}=1, p=\right.$ 0.0401 ) increased from 0.176 to 0.378 in the presence of tour boats, whereas the transition probability from traveling to foraging $\left(X^{2}=5.0145 ; \mathrm{df}=1 ; p=0.0252\right)$ decreased from 0.304 to 0.224 as an effect of tour boat presence (Fig. 3).

\section{Activity budgets}

There was a significant difference in dolphin activity budgets between control and impact situations $\left(X^{2}=31.0336 ; \mathrm{df}=2 ; p<0.001\right)$. Dolphins spent a significantly smaller proportion of their time foraging $\left(X^{2}=22.4266 ; \mathrm{df}=1 ; p<0.001\right)$ and more time traveling $\left(X^{2}=25.5354 ; \mathrm{df}=\right.$ $1 ; p=<0.001$ ) in the presence of tour boats (Fig. 4). Foraging was the dominant activity state during both control and impact situations ( $61 \%$ and $48 \%$, respectively), followed by traveling (32 and $45 \%$, respectively). During impact situations, the time budget for foraging decreased by $13 \%(61 \%$ to $48 \%$ ) and the budget for traveling increased by the same percentage, $13 \%$ (32 to $45 \%)$.

\section{Activity bout length}

There was a significant difference in the average length of activity bouts between control and impact situations for all three-activity states (Fig. 5). The length of foraging and socializing bouts were significantly reduced when tour boats were present, whereas traveling bouts were significantly longer. Bout length decreased significantly for foraging dolphins $(\mathrm{t}=37.37, \mathrm{df}=$ $729 ; p<0.0001)$ by $3.4 \mathrm{~min}(95 \%$ CI: $3.19-3.55)$, or $20 \%$, and decreased for socializing dolphins $(\mathrm{t}=12.16 ; \mathrm{df}=103 ; p<0.0001)$ by $3.5 \mathrm{~min}(95 \%$ CI: $2.97-4.11)$, or $36 \%$. Conversely, the duration of traveling bouts for dolphins increased significantly $(\mathrm{t}=-20.65 ; \mathrm{df}=461 ; p<$ 0.0001 ) by $2.6 \mathrm{~min}$ ( $95 \% \mathrm{CI}:-2.89--2.39$ ), or $30 \%$, during tour boat interactions.

\section{Recovery time}

The average time it took for dolphins to return to their initial activity state (recovery time) was also altered in the presence of tour boats. Once disrupted by tour boats, foraging dolphins took $1.4 \mathrm{~min}(29 \%)$ longer to return to this state, with an increase from $4.9 \mathrm{~min}$ to $6.3 \mathrm{~min}$. Similarly, recovery time for socializing dolphins increased by $3.3 \mathrm{~min}(8 \%)$ when tour boats were present, with an increase from $41.5 \mathrm{~min}$ to $44.7 \mathrm{~min}$. In contrast, the time taken to return to traveling decreased with $2.9 \mathrm{~min}(31 \%)$ during tour boat interactions, from $9.5 \mathrm{~min}$ to $6.6 \mathrm{~min}$.

\section{Discussion}




\section{Effects of tour boats on dolphin activity patterns and activity budgets}

366 The results of this study provide evidence that tour boat interactions significantly affect

367 bottlenose dolphin behavior in Dolphin Bay, Bocas del Toro, Panama. The Markov chain

368 transition analysis showed that the activity states of dolphins were significantly different in the

369 presence of tour boats than during control conditions. More specifically, when interacting with

370

371 tour boats, dolphins were significantly less likely to begin foraging when traveling and more

372

373 likely to begin traveling when socializing. Once disrupted by tour boats, dolphins took nearly $30 \%$ longer to return to foraging when compared to control conditions, and traveling dolphins more quickly returned to traveling (31\%). These changes in activity states were of sufficient magnitude to cause significant changes in the activity budget of dolphins. Overall, dolphins spent a significantly smaller proportion of their time foraging and more time traveling in the presence of tour boats. Furthermore, the average length of time that dolphins spent foraging and socializing was significantly reduced during tour boat interactions and the average time spent traveling was increased, suggesting that dolphin feeding and social behavior was consistently interrupted by tourism and dolphins instead spent more time traveling when tour boats were present, perhaps at the cost of other biologically important activities. Boat-based tourism occurs year-round in Dolphin Bay, where high site fidelity of dolphins likely increases the chance of interactions with specific members of this community. Peak tourism season occurs from December to May during the dry months, while the low-season occurs during the rainy season (June-November). However, up to 39 boats have been reported interacting with dolphins over a period of one-hour in Dolphin Bay during the low season for tourism, demonstrating that dolphins are exposed to high levels of boat tourism year-round (May-Collado et al., 2017). The majority of interactions between tour boats and dolphin groups in this study included 1 to 2 boats $(55 \%)$, which means that our measured effect could be conservative if we assume that the effect of tour boat interactions increases with the number of tour boats present.

The decrease in time spent foraging during tourism activities could be of biological importance to the Dolphin Bay community. Foraging was the dominant activity for dolphins in this study, therefore, it is reasonable to assume that Dolphin Bay represents an important feeding habitat for dolphins. Barragán-Barrera et al. (2019) found that despite the wide availability of other prey species found throughout the archipelago, the dolphins of Bocas del Toro primarily feed on dwarf round herring (Jenkinsia lamprotaenia), a small and low-calorie prey. Repeated disruption to a critical activity like foraging can result in fewer feeding events, which could lead to reduced energy acquisition for individuals. This could in turn negatively affect the body condition of animals over time, and ultimately impact individual survival and reproductive success (Christiansen et al., 2013; Christiansen \& Lusseau, 2015; New et al., 2015). The dolphins' activity budget showed that the proportion of time allocated to foraging under tourism conditions was reduced by the same proportion as their traveling activity was increased, perhaps indicating that dolphins are traveling more to avoid tour boats at the expense of foraging. Studies suggest that reduced energy acquisition resulting from lost foraging opportunities may have a bigger impact on the energy balance and body condition of individuals than energy-costly activities, such as traveling or vertical avoidance (Noren et al., 2016).

The impact of tourism on cetacean social behavior has been given less attention than the effects on other critical behaviors such as foraging, traveling and resting, however, the influence of boat disturbance on dolphin socialization should not be underestimated. Socializing plays an important role in the reproductive success of dolphins and disruption to this activity could result in negative impacts to reproductive success (Lusseau, Slooten \& Currey, 2006). In this study, 
411 socializing dolphins were $20 \%$ more likely to switch to traveling in the presence of tour boats 412 and the average length of socializing bouts decreased significantly by $36 \%$ in the presence of a 413 tour boat. Previous research in the southern and southeastern United States found bottlenose 414 dolphin social behavior to be highest in the spring and summer months, suggesting that the rate 415 of dolphin socialization may vary seasonally, perhaps as a function of female reproductive 416 receptiveness (Shane et al., 1986). High levels of boat traffic year-round in Dolphin Bay, 417 therefore, could negatively impact reproduction in this community. More research is needed to 418 identify seasonal trends in dolphin socialization in Dolphin Bay, including identification of a 419 breeding season, as well as the overall social network of the community.

The accepted framework for inferring the costs of tourism on cetacean behavioral ecology suggests that increased energetic challenges, either through reduced foraging opportunities or added traveling costs, can lead to reduced fitness for individuals. If the energetic challenges of avoidance behaviors become too great, or individuals are unable to compensate for these effects, dolphins may shift into long-term avoidance of Dolphin Bay. Based on the high site fidelity of dolphins (population size $=37$ ), Dolphin Bay is a preferred area for dolphins and degradation of this habitat, either through acoustic pollution (e.g. boat engine noise) and/or boat proximity and behavior (e.g. aggressive approaches), could lead to displacement of more sensitive animals from boat disturbance areas, perhaps causing a long-term shift into lowerquality habitat. Dolphin watching tourism has been associated with changes in residency patterns and long-term area avoidance in other geographical areas (Lusseau, 2005; Bejder et al., 2006a). However, it is important to note that inferring the biological relevance of multiple behavioral responses of cetaceans to disturbance is often difficult, especially when considering the high plasticity and behavioral variability of delphinids (Shane et al., 1986). The Dolphin Bay community may be behaviorally compensating for the observed decline in foraging activity in other ways, for example, by foraging at times of the day not captured by this study or perhaps even at night. Conversely, the resident dolphins of Dolphin Bay do not necessarily reflect a habituated population but instead may reflect a subset of the population that are ecologically or socially constrained to the area and are being disproportionately exposed to tourism activities. Individual responses to disturbance result from a behavioral trade-off process between the costs of staying in a preferred area under conditions of disturbance and the benefits accrued from remaining. Dolphins may perceive tour boats as a form of risk and respond with anti-predator avoidance behaviors, which carry energetic costs, as animals must make behavioral trade-offs between energy acquiring activities (e.g. foraging) and energy-consumptive activities (e.g. traveling) (Gill et al., 1996). For individual animals with physiologic constraints such as calf dependency, the local abundance of herring as a reliable food source in Dolphin Bay may outweigh the cost of moving to less suitable foraging habitat.

Tourism impact studies of the Dolphin Bay population began in 2006, however, dolphin tourism was present in the archipelago before studies were initiated, therefore it is unknown if the population was always small or if less tolerant animals have already been displaced from Dolphin Bay due to high levels of acoustic and/or behavioral disturbance. In the latter case, tourism activities may already be endangering the viability of this small population because of the increased cumulative exposure that each individual incurs. Individuals unable to flee are more likely to incur the cumulative effects of disturbance and suffer reduced fitness, expressed through decreased reproductive success (Gill, Norris \& Sutherland, 2001).

\section{Recommendations for dolphin watching tourism in Bocas del Toro}


457 Currently, the Panamanian government's whale watching regulations stipulate that no more than 458 two tour boats are permitted to interact with dolphins at one time and boats must maintain a 459 distance of $100 \mathrm{~m}$ or more from the animals; however, in a 2013 study of tour boat interactions 460 in Dolphin Bay, three or more tour boats were within distance of $50 \mathrm{~m}$ or less $70 \%$ of the time, 461 showing a high level of noncompliance with these regulations and minimal action from the 462 Panamanian government in local enforcement, despite repeated recommendations by the IWC 463 (Sitar et al., 2016). In 2012, three calves were killed by boat strikes in Dolphin Bay, and a number of dolphins in this study were observed with new and old propeller-type injuries, suggesting that boat traffic is not only an indirect stressor to dolphins, but also a direct physical threat to their survival (Trejos-Lasso \& May-Collado, 2015). Agent-based modeling simulating the effects of cetacean watching on small, genetically isolated populations demonstrate that even low levels of boat disturbance can lead to a decline in population size and possibly even local extinction (Lusseau \& Bejder, 2007).

Further assessment of which vital rates are impacted most by disturbance in this population (e.g. survival and/or reproduction) could assist in the development of context-specific tourism management strategies. In New Zealand, an observed decline in local abundance of bottlenose dolphins was correlated with unusual high calf mortality (Tezanos-Pinto et al., 2015). Management strategies that are aimed at protecting the reproductive rate of the Dolphin Bay population could be an effective preventative measure to anticipated decline of this population. For example, eliminating or strongly limiting tour boat interactions with groups containing mother-calf pairs should be strongly considered. Additionally, delineation of protected zones for dolphins based on their habitat preferences for critical biological activities (e.g. foraging, socializing and resting) could be of importance in minimizing disturbance to foraging activities of dolphins in Dolphin Bay, as well as affording ample space for undisturbed socialization activities.

Ecotourism is a highly profitable industry in Bocas del Toro, with the potential to provide economic benefits to local communities as well as promote conservation of the marine environment. However, the rapid, uncontrolled growth of tour boat activities and the aggressive practices of some tour boat operators around dolphin groups is currently of high conservation concern. In 2015 the IWC called for the Panamanian government to enforce its whale watching regulations, and there has since been a significant effort to educate and train boat operators on how to safely operate boats around dolphins. However, three major issues remain unaddressed: (1) the high turn-over of boat-captains dilutes training efforts, (2) the current lack of a licensing process promotes high boat traffic and low rates of compliance, and (3) boat tours do not necessarily reflect tourists interests (e.g. tourists prefer to see sloths and monkeys than dolphins) (May-Collado et al., 2015, 2017). The failure to address these issues (despite increased boat operator training efforts) means that dolphins continue to be affected by high levels of boat tourism, highlighting the need for urgent reform of tourism practices and marketing to protect the viability of the local dolphin population and the tourism industry (Sitar et al., 2016).

Boat operators are not currently licensed in Bocas del Toro; therefore, establishing a permitting process for dolphin watching tourism appears to be a reasonable next step. However, more governmental involvement is needed for effective issuing enforcement of permits.

Currently, collaboration between scientists, governmental officials, community leaders and local stakeholders are paving the way for a community-based tourism management initiative through development of a "bottom-up" boat operator training and permitting program that will help limit the number of tour boats in Dolphin Bay, as well as empower licensed operators with the skills 
503 and training needed to conduct tourism experiences based on best practices. Effectiveness of

504 these strategies should continue to be monitored and supported as well as continuing to appeal to

505 the Panamanian government for support and oversight. Further consideration should also be

506 given by the IUCN to evaluate the conservation status of this small, genetically distinct

507 community of T. truncatus to reflect its actual threat level based on the behavioral results of this

508 study, as well as a number of other studies demonstrating low genetic diversity of this

509 community and tour boat effects on short-term behavior and acoustic structure.

510

\section{Conclusions}

512 The results of this study demonstrate that current levels of dolphin watching tourism in Dolphin

513 Bay are affecting dolphin activity patterns in sufficient quantity to alter their activity budgets.

514 Dolphins foraged less and traveled more in the presence of tour boats, the average length of time 515 that dolphins spent foraging and socializing was significantly reduced, and the average time 516 spent traveling increased during tour boat interactions. These changes in activity patterns may 517 ultimately carry energetic costs for individuals and have long-term negative implications for 518 individual vital rates and population dynamics. The energetic consequences of reduced foraging 519 and increased traveling activity are likely to be more pronounced for mother-calf pairs who are 520 already constrained by their reproductive physiology. More research into maternal behaviors and 521 calf survivability is needed to understand the relationship between energetic costs and boat 522 tourism effects. The behavioral results from this study provide further evidence that the Bocas 523 del Toro bottlenose dolphin population is highly vulnerable to the cumulative effects of tourism 524 activities, highlighting the need for identification of "at-risk" conservation management units for 525 this small, genetically distinct population. 
526

527

528

529

530

531

532

533

534

535

536

537

538

539

540

541

542

543

544

545

546

547

548

549

550

551

552

553

554

555

556

557

558

559

560

561

562

563

564

565

566

567

568

569

570

571

\section{Acknowledgements}

A big thank you to the STRI Bocas del Toro field station and staff for providing a research boat, logistical support and a great lab space to work in. To the boat captains who assisted with this project, thank you for your knowledge and hard work. A special thank you to our boat captain D. Georget, for his patience with the research process and for his dedication to the conservation of the Bocas dolphins. To all of the inspirational ladies of Panacetacea's Bocas Dolphin research team: S. Quinones-Lebron, D. Barragán-Barrera, M. Gamboa-Poveda and L. Trejos. A big thank you to our field assistants Cole, Giselle and Katherine (KC) for all of their hard work and dedication to data collection, and to advisors, colleagues and friends for their invaluable support in data analysis and reviewing this manuscript. This study was conducted under the research permit SE/A 79-14 under Dr. L. J. May-Collado.

\section{References}

Altmann, J. 1974. Observational study of behavior: sampling methods. Behaviour 49:227-267. DOI 10.1163/156853974X00534.

Barragán-Barrera, D. C., L. J. May-Collado, G. Tezanos-Pinto, V. Islas-Villanueva, C. A. Correa-Cárdenas, and S. Caballero. 2017. High genetic structure and low mitochondrial diversity in bottlenose dolphins of the Archipelago of Bocas del Toro, Panama: A population at risk? PLOS ONE 12:e0189370. DOI 10.1371/journal.pone.0189370.

Barragán-Barrera, D. C., A. Luna-Acosta, L. J. May-Collado, C. J., Polo-Silva, F. G. RietSapriza, P. Bustamante, M. P. Hernández-Ávila, N. Vélez, N. Farías-Curtidor, and S. Caballero. 2019. Foraging habits and levels of mercury in a resident population of bottlenose dolphins (Tursiops truncatus) in Bocas del Toro Archipelago, Caribbean Sea, Panama. Marine Pollution Bulletin 145:343-356. DOI 10.1016/j.marpolbul.2019.04.076.

Baş, A., F. Christiansen, B. Oztürk, A. Oztürk, M. A. Erdoğan, and L. J. Watson. 2017. Marine vessels alter the behaviour of bottlenose dolphins Tursiops truncatus within the Istanbul Strait, Turkey. Endangered Species Research 34:1-14. DOI 10.3354/esr00836.

Bejder, L., S. M. Dawson, and J. A. Harraway. 1999. Responses by Hector's Dolphins to Boats and Swimmers in Porpoise Bay, New Zealand. Marine Mammal Science 15:738-750. DOI 0.1111/j.1748-7692.1999.tb00840.x.

Bejder, L., A. Samuels, H. Whitehead, and N. Gales. 2006a. Interpreting short-term behavioural responses to disturbance within a longitudinal perspective. Animal Behaviour 72:1149-1158. DOI 10.1016/j.anbehav.2006.04.003.

Bejder, L., A. Samuels, H. Whitehead, N. Gales, J. Mann, R. Connor, M. Heithaus, J. WatsonCapps, C. Flaherty, and M. Krützen. 2006b. Decline in relative abundance of bottlenose dolphins exposed to long-term disturbance. Conservation Biology 20:1791-1798. DOI 10.1111/j.1523-1739.2006.00540.x.

Buckstaff, K. C. 2004. Effects of watercraft noise on the acoustic behavior of bottlenose dolphins, Tursiops truncatus, in Sarasota Bay, Florida. Marine Mammal Science 20:709-725. DOI 10.1111/j.1748-7692.2004.tb01189.x.

Christiansen, F., C. G. Bertulli, M. H. Rasmussen, and D. Lusseau. 2015. Estimating cumulative exposure of wildlife to non-lethal disturbance using spatially explicit capture-recapture models. Journal of Wildlife Management 79:311-324. DOI 10.1002/jwmg.836.

Christiansen, F., and D. Lusseau. 2015. Linking Behavior to Vital Rates to Measure the Effects of Non-Lethal Disturbance on Wildlife. Conservation Letters 8:424-431. DOI 10.1111/conl.12166. 
572 Christiansen, F., D. Lusseau, E. Stensland, and P. Berggren. 2010. Effects of tourist boats on the

573

574

575

576

577

578

579

580

581

582

583

584

585

586

587

588

589

590

591

592

593

594

595

596

597

598

599

600

601

602

603

604

605

606

607

608

609

610

611

612

613

614

615

616

617 behaviour of Indo-Pacific bottlenose dolphins off the south coast of Zanzibar. Endangered Species Research 11:91-99. DOI 10.3354/esr00265.

Christiansen, F., M. H. Rasmussen, and D. Lusseau. 2013. Inferring activity budgets in wild animals to estimate the consequences of disturbances. Behavioral Ecology 24:1415-1425.

Christiansen, F., M. H. Rasmussen, and D. Lusseau. 2014. Inferring energy expenditure from respiration rates in minke whales to measure the effects of whale watching boat interactions. Journal of Experimental Marine Biology and Ecology 459:96-104. DOI 10.1016/j.jembe.2014.05.014.

Christiansen, F., and D. Lusseau. 2015. Linking behavior to vital rates to measure the effects of non-lethal disturbance on wildlife. Conservation Letters 8:424-431. DOI 10.1111/conl.12166.

Currey, R. J. C., S. M. Dawson, E. Slooten, K. Schneider, D. Lusseau, O. J. Boisseau, P. Haase, and J. A. Williams. 2009. Survival rates for a declining population of bottlenose dolphins in Doubtful Sound, New Zealand: an information theoretic approach to assessing the role of human impacts. Aquatic Conservation: Marine and Freshwater Ecosystems 19:658-670. DOI 10.1002/aqc. 1015.

Duffus, D. A., and P. Dearden. 1990. Non-consumptive wildlife-oriented recreation: a conceptual framework. Biological Conservation 53:213-231.

Frid, A., and L. M. Dill. 2002. Human-caused disturbance stimuli as a form of predation risk. Conservation Ecology 6:11.

Gibson, Q. A., and J. Mann. 2008. Early social development in wild bottlenose dolphins: sex differences, individual variation and maternal influence. Animal Behaviour 76:375-387. DOI 10.1016/j.anbehav.2008.01.021.

Gill, J. A., K. Norris, and W. J. Sutherland. 2001. Why behavioural responses may not reflect the population consequences of human disturbance. Biological Conservation 97:265-268.

Gill, J. A., W. J. Sutherland, and A. R. Watkinson. 1996. A Method to Quantify the Effects of Human Disturbance on Animal Populations. Journal of Applied Ecology 33:786-792.

Guttorp, P., and V. N. Minin. 1995. Stochastic Modeling of Scientific Data. CRC Press.

Hawkins, E. R., R. Harcourt, L. Bejder, L. O. Brooks, A. Grech, F. Christiansen, H. Marsh, and P. L. Harrison. 2017. Best practice framework and principles for monitoring the effect of coastal development on marine mammals. Frontiers in Marine Science 4:59. DOI 10.3389/fmars.2017.00059.

Heiler, J., S. H. Elwen, H. J. Kriesell, and T. Gridley. 2016. Changes in bottlenose dolphin whistle parameters related to vessel presence, surface behaviour and group composition. Animal Behaviour 117:167-177. DOI 10.1016/j.anbehav.2016.04.014.

Higham, J. E. S., L. Bejder, S. J. Allen, P. J. Corkeron, and D. Lusseau. 2015. Managing whalewatching as a non-lethal consumptive activity. Journal of Sustainable Tourism 24:73-90. DOI 10.1080/09669582.2015.1062020.

International Whaling Commission. 2019. Report of the Scientific Committee. Page Journal of Cetacean Research and Management. Available at https://archive.iwc.int/pages/search.php?search=! collection73\# (accessed September 23, 2019)

Kaufmann, K., and R. C. Thompson. 2005. Water temperature variation and the meteorological and hydrographic environment of Bocas Del Toro, Panama. Caribbean Journal of Science 41:392-413. 
618 Linzer D.A., and J.B. Lewis. 2011. poLCA: An R Package for Polytomous Variable

619 Latent Class Analysis. Journal of Statistical Software 10: 1-29.

620

621

622

623

624

625

626

627

628

629

630

631

632

633

634

635

636

637

638

639

640

641

642

643

644

645

646

647

648

649

650

651

652

653

654

655

656

657

658

659

660

661

662

663

Lusseau, D. 2003. Effects of tour boats on the behavior of bottlenose dolphins: using Markov chains to model anthropogenic impacts. Conservation Biology 17:1785-1793. DOI 10.1111/j.1523-1739.2003.00054.x.

Lusseau, D. 2005. Residency pattern of bottlenose dolphins (Tursiops spp.) in Milford Sound, New Zealand is related to boat traffic. Marine Ecological Progress Series 295:265-272. DOI 10.3354/meps295265.

Lusseau, D., and L. Bejder. 2007. The long-term consequences of short-term responses to disturbance experiences from whalewatching impact assessment. International Journal of Comparative Psychology 20:2.

Lusseau, D., L. Slooten, and R. J. C. Currey. 2006. Unsustainable dolphin-watching tourism in Fiordland, New Zealand. Tourism in Marine Environments 3:1-5. DOI $10.3727 / 154427306779435184$.

Mann, J. 1999. Behavioral Sampling Methods for Cetaceans: A Review and Critique. Marine Mammal Science 15:102-122. DOI 10.1111/j.1748-7692.1999.tb00784.x.

Mann, J., and B. L. Sargeant. 2003. Like mother, like calf: the ontogeny of foraging traditions in wild Indian Ocean bottlenose dolphins (Tursiops sp.) The biology of traditions: Models and Evidence 236-266.

May-Collado, L. J., D. C. Barragán-Barrera, S. G. Quiñones-Lebrón, and W. Aquino-Reynoso. 2012. Dolphin watching boats impact on habitat use and communication of bottlenose dolphins in Bocas del Toro, Panama during 2004, 2006-2010. Scientific Committee of the International Whaling Commission; SC/64/WW/2.

May-Collado, L. J., S. Quinones-Lebron, D. C. Barragán-Barrera, J. D. Palacios, M. Gamboa, M. Poveda, and A. Kassamali-Fox. 2015. The Bocas del Toro's dolphin watching industry relies on a small community of bottlenose dolphins: implications for management. Scientific Committee of the International Whaling Commission; SC/66a/WW/10.

May-Collado, L. J., B. Perez, D. C. Barragán-Barrera, K. Gonzales, N. Swack, M. Gamboa Poveda, and J. D. Palacios-Alfaro. 2019. An update of the conservation status of the bottlenose dolphins of Bocas del Toro Panama: Female calving intervals and calf survivorship. Scientific Committee of the International Whaling Commission: $\mathrm{SC} / 68 \mathrm{~A} / \mathrm{WW} / 03$.

May-Collado, L. J., and S. G. Quiñones-Lebrón. 2014. Dolphin changes in whistle structure with watercraft activity depends on their behavioral state. Journal of the Acoustical Society of America 135:193-198. DOI 10.1121/1.4869255.

May-Collado, L. J., and D. Wartzok. 2008. A comparison of bottlenose dolphin whistles in the Atlantic Ocean: factors promoting whistle variation. Journal of Mammalogy 89:1229-1240. DOI 10.1644/07-MAMM-A-310.1.

Meissner, A. M., F. Christiansen, E. Martinez, M. D. M. Pawley, M. B. Orams, and K. A. Stockin. 2015. Behavioural effects of tourism on oceanic common dolphins, Delphinus sp., in New Zealand: The effects of Markov analysis variations and current tour operator compliance with regulations. PLoS ONE 10:e0116962. DOI 10.1371/journal.pone.0116962.

Mustika, P. L. K., A. Birtles, Y. Everingham, and H. Marsh. 2013. The human dimensions of wildlife tourism in a developing country: Watching spinner dolphins at Lovina, Bali, Indonesia. Journal of Sustainable Tourism 21:229-251. DOI 10.1080/09669582.2012.692881. 
664 New, L. F., A. J. Hall, R. Harcourt, G. Kaufman, E. C. M. Parsons, H. C. Pearson, A. M.

665

666

667

668

669

670

671

672

673

674

675

676

677

678

679

680

681

682

683

684

685

686

687

688

689

690

691

692

693

694

695

696

697

698

699

700

701

702

703

704

705

706

707

708

709 impacts. Ocean and Coastal Management 115:10-16. DOI 10.1016/j.ocecoaman.2015.04.006.

Noren, D. P., M. M. Holt, R. C. Dunkin, N. M. Thometz, and T. M. Williams. 2016. Comparative and cumulative energetic costs of odontocete responses to anthropogenic disturbance. Proceedings of Meetings on Acoustics 27:040011.

Nowacek, S. M., R. S. Wells, and A. R. Solow. 2001. Short-term effects of boat traffic on bottlenose dolphins, Tursiops truncatus. Marine Mammal Science 17:673-688. DOI 10.1111/j.1748-7692.2001.tb01292.x.

O'Connor, S., R. Campbell, H. Cortez, and T. Knowles, 2009. Whale Watching Worldwide: tourism numbers, expenditures and expanding economic benefits. International Fund for Animal Welfare, Yarmouth, Massachusetts.

Pérez-Jorge, S., M. Louzao, D. Oro, T. Pereira, C. Corne, Z. Wijtten, I. Gomes, J. Wambua, and F. Christiansen. 2016. Estimating the cumulative effects of nature-based tourism in a coastal dolphin population from southern Kenya. Deep Sea Research Part II: Topical Studies in Oceanography 140:278-289. DOI 10.1016/j.dsr2.2016.08.011.

Pirotta, E., and D. Lusseau. 2015. Managing the wildlife tourism commons. Ecological Applications 25:729-741. DOI 10.1890/14-0986.1.

Pirotta, E., P. M. Thompson, B. Cheney, C. R. Donovan, and D. Lusseau. 2015. Estimating spatial, temporal and individual variability in dolphin cumulative exposure to boat traffic using spatially explicit capture-recapture methods. Animal Conservation 18:20-31. DOI 10.1111/acv.12132.

R Team. 2013. R Development Core Team. R: A language and environment for statistical computing. $R$ Foundation for Statistical Computing.

Resolución No. DM-0530-2017. Gaceta Oficial Digital № 28389-B, Panamá, República de Panamá. De 18 de octubre de 2017.

Samuels, A., Bejder, L., Constantine, R. and S. Heinrich. 2003. A review of swimming with wild cetaceans with a special focus on the Southern Hemisphere. In: Gales, N., Hindell, M., Kirkwood, R., (Eds.), Marine Mammals and Humans: Towards a Sustainable Balance. CSIRO Publishing, Collingwood, Australia.

Senigaglia, V., F. Christiansen, L. Bejder, D. Gendron, D. Lundquist, D. P. Noren, A. Schaffar, J. C. Smith, R. Williams, E. Martinez, and K. Stockin. 2016. Meta-analyses of whalewatching impact studies: comparisons of cetacean responses to disturbance. Marine Ecology Progress Series 542:251-263. DOI 10.3354/meps11497.

Shane, S. H., R. S. Wells, and B. Würsig. 1986. Ecology, behavior and social organization of the bottlenose dolphin: a review. Marine Mammal Science 2:34-63.

Sitar, A., L. J. May-Collado, A. J. Wright, E. Peters-Burton, L. Rockwood, and E. C. M. Parsons. 2016. Boat operators in Bocas del Toro, Panama display low levels of compliance with national whale-watching regulations. Marine Policy 68:221-228. DOI 10.1016/j.marpol.2016.03.011.

Spedicato G. 2017. "Discrete Time Markov Chains with R.” The R Journal. R package version 0.6.9.7, https://journal.r-project.org/archive/2017/RJ-2017-036/index.html.

Stensland, E., and P. Berggren. 2007. Behavioural changes in female Indo-Pacific bottlenose dolphins in response to boat-based tourism. Marine Ecology Progress Series 332:225-234. DOI 10.3354/meps332225. 
710 Stockin, K. A., D. Lusseau, V. Binedell, N. Wiseman, and M. B. Orams. 2008. Tourism affects

711 the behavioural budget of the common dolphin Delphinus sp. in the Hauraki Gulf, New

712 Zealand. Marine Ecology Progress Series 355:287-295. DOI 10.3354/meps07386.

713 Tezanos-Pinto, G., R. Constantine, J. Berghan, and C. S. Baker. 2015. High calf mortality in

714 bottlenose dolphins in the Bay of Islands, New Zealand - a local unit in decline. Marine

715 Mammal Science 31:540-559. DOI 10.1111/mms.12174.

716 Tyne, J. A., F. Christiansen, H. L. Heenehan, D. W. Johnston, and L. Bejder. 2018. Chronic

717

718

719 exposure of Hawaii Island spinner dolphins (Stenella longirostris) to human activities. Royal Society Open Science 5:171506. DOI 10.1098/rsos.171506.

Wells, R. S., A. Natoli, A. and G. Braulik. 2019. Tursiops truncatus. The IUCN Red List of Threatened Species: T22563A50377908.

Williams, R., D. Lusseau, and P. S. Hammond. 2006. Estimating relative energetic costs of human disturbance to killer whales (Orcinus orca). Biological Conservation 133:301-311. DOI 10.1016/j.biocon.2006.06.010.

Würsig, B., and M. Würsig. 1977. The photographic determination of group size, composition, and stability of coastal porpoises Tursiops truncatus. Science 198:755-756. 


\section{Figure 1}

Map of the study site in the Bocas del Toro archipelago, Panama.

This study took place from July to October of 2014 in Dolphin Bay. Dolphin Bay sustains a small, resident population of bottlenose dolphins that is exposed to daily tour boats yearround.

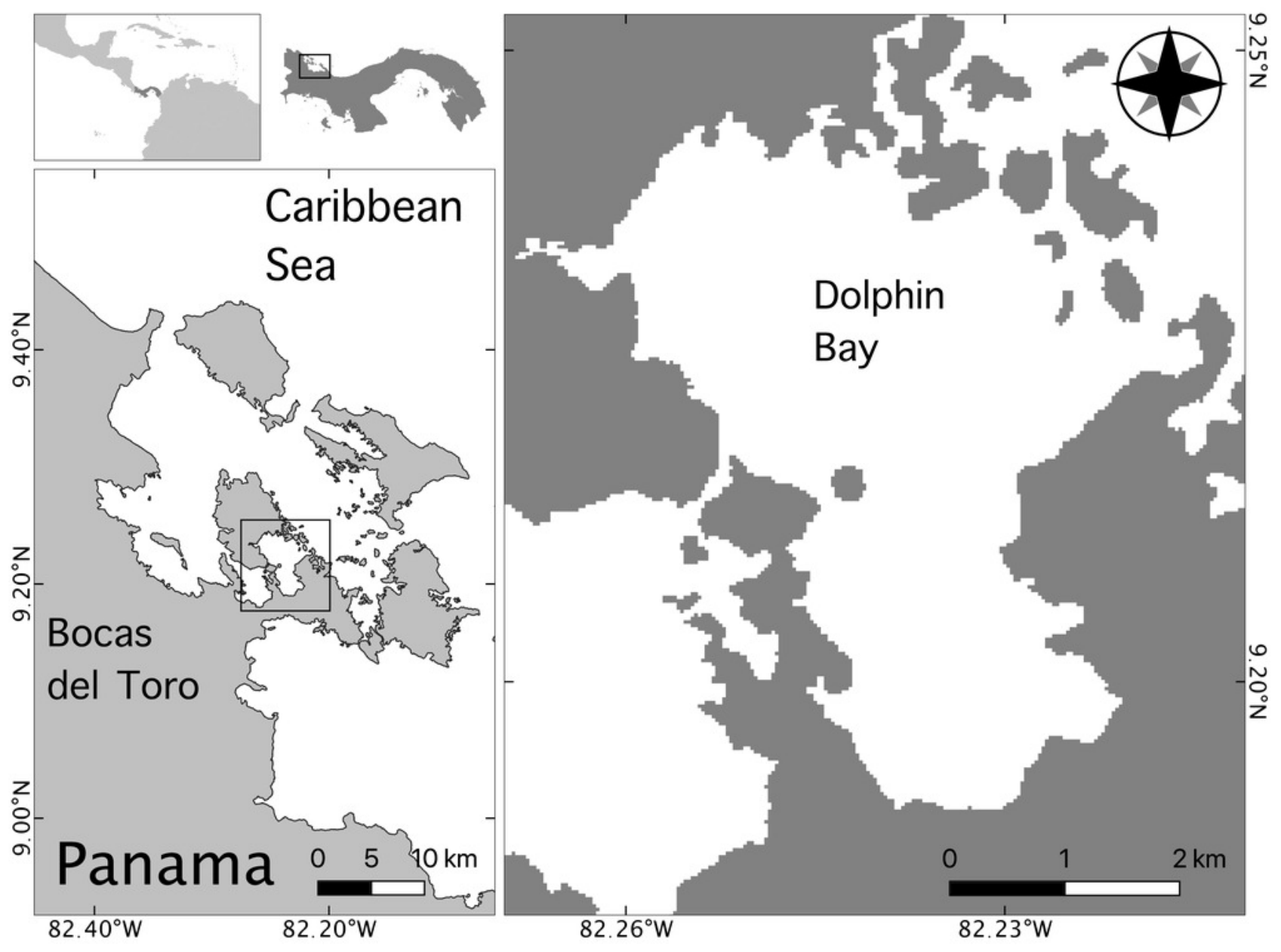


Figure 2

Markov chains representing transition probabilities between activity states during control $(A)$ and impact $(B)$ situations.

Values represent transition probabilities and the thickness of the arrows represent the magnitude of these transition probabilities. 


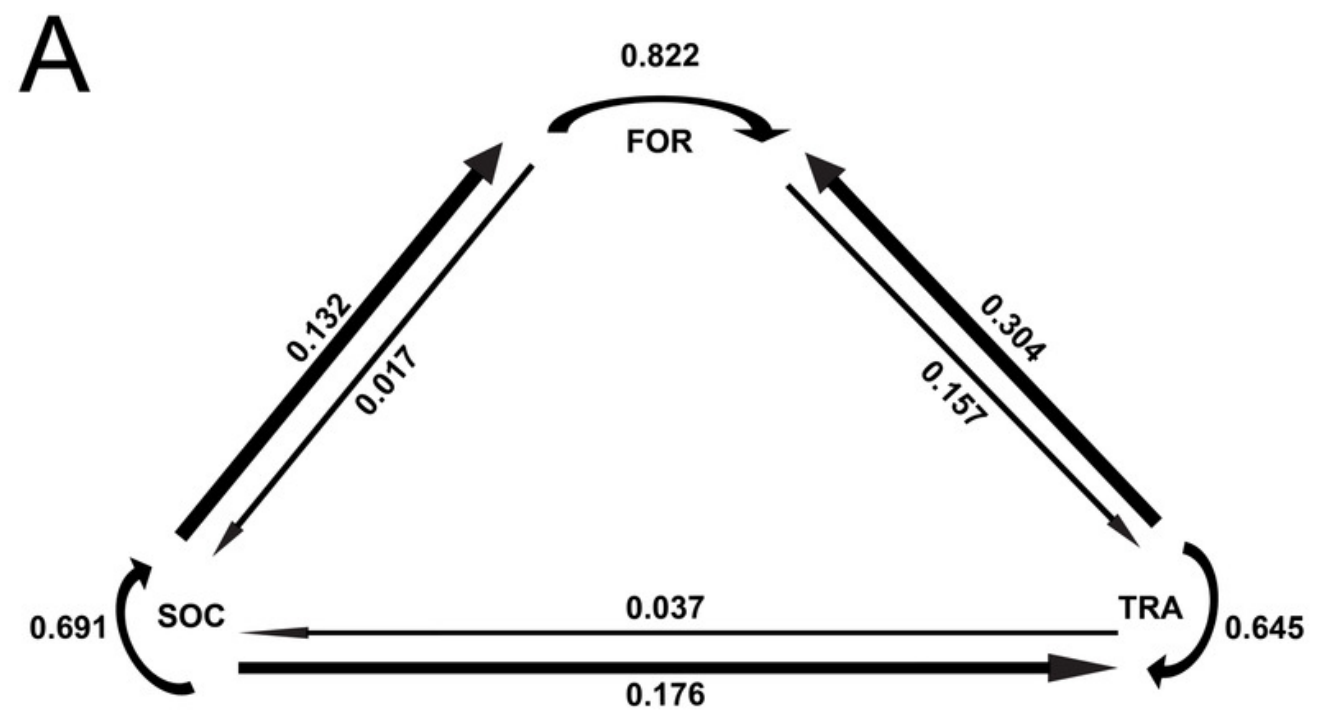

B

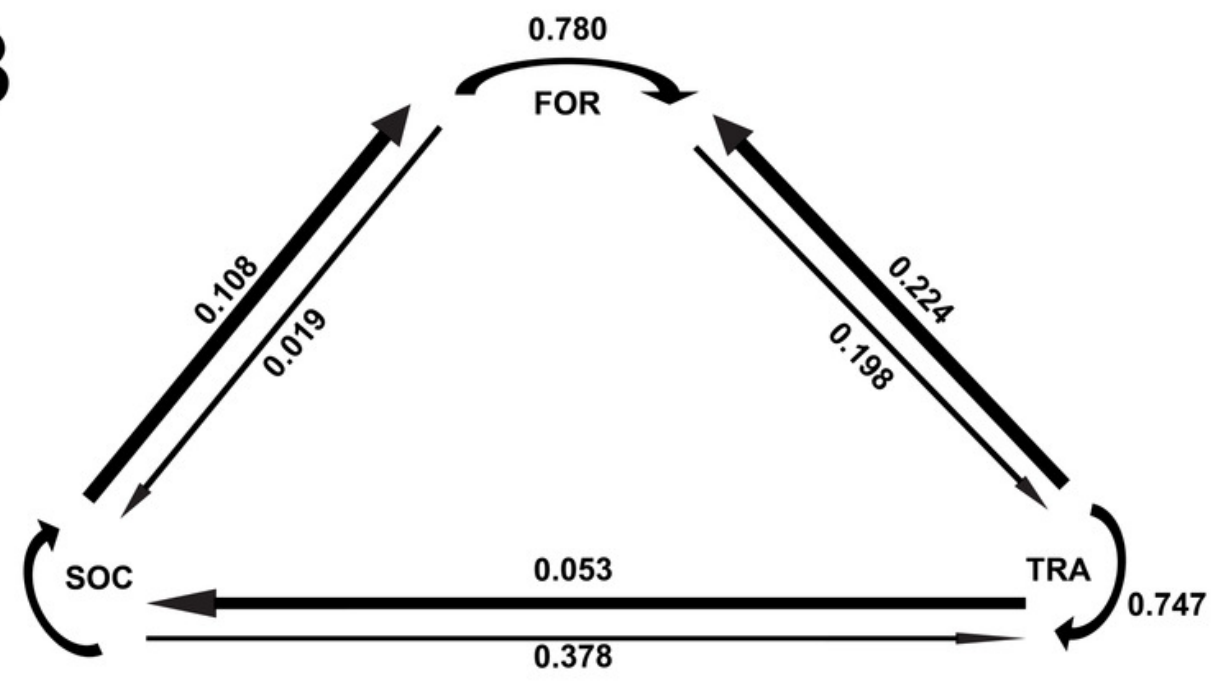


Figure 3

Effect of tour boats on the transition probability between activity states for bottlenose dolphins.

Positive values indicate an increase in transition probability when boats were present and negative values indicate a decrease. Significant differences $(p<0.05)$ are denoted by an asterisk.

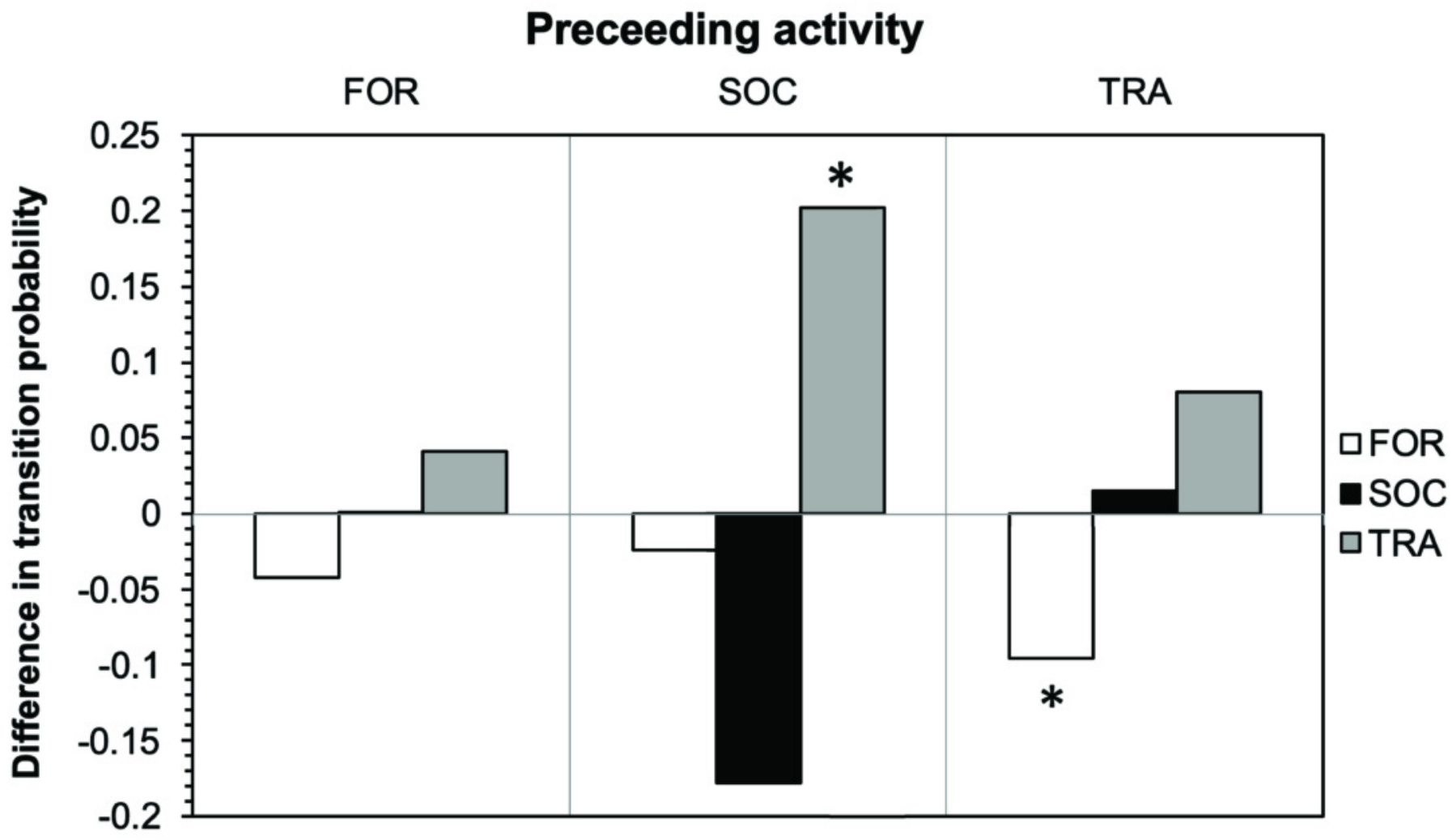

Suceeding activity 
Figure 4

The activity budget (the proportion of time spent in each activity state) of bottlenose dolphins in Dolphin Bay in the absence (Control) and presence (Impact) of tour boats.

Error bars represent 95\% confidence intervals. Significant differences $(p<0.05)$ are denoted by an asterisk.

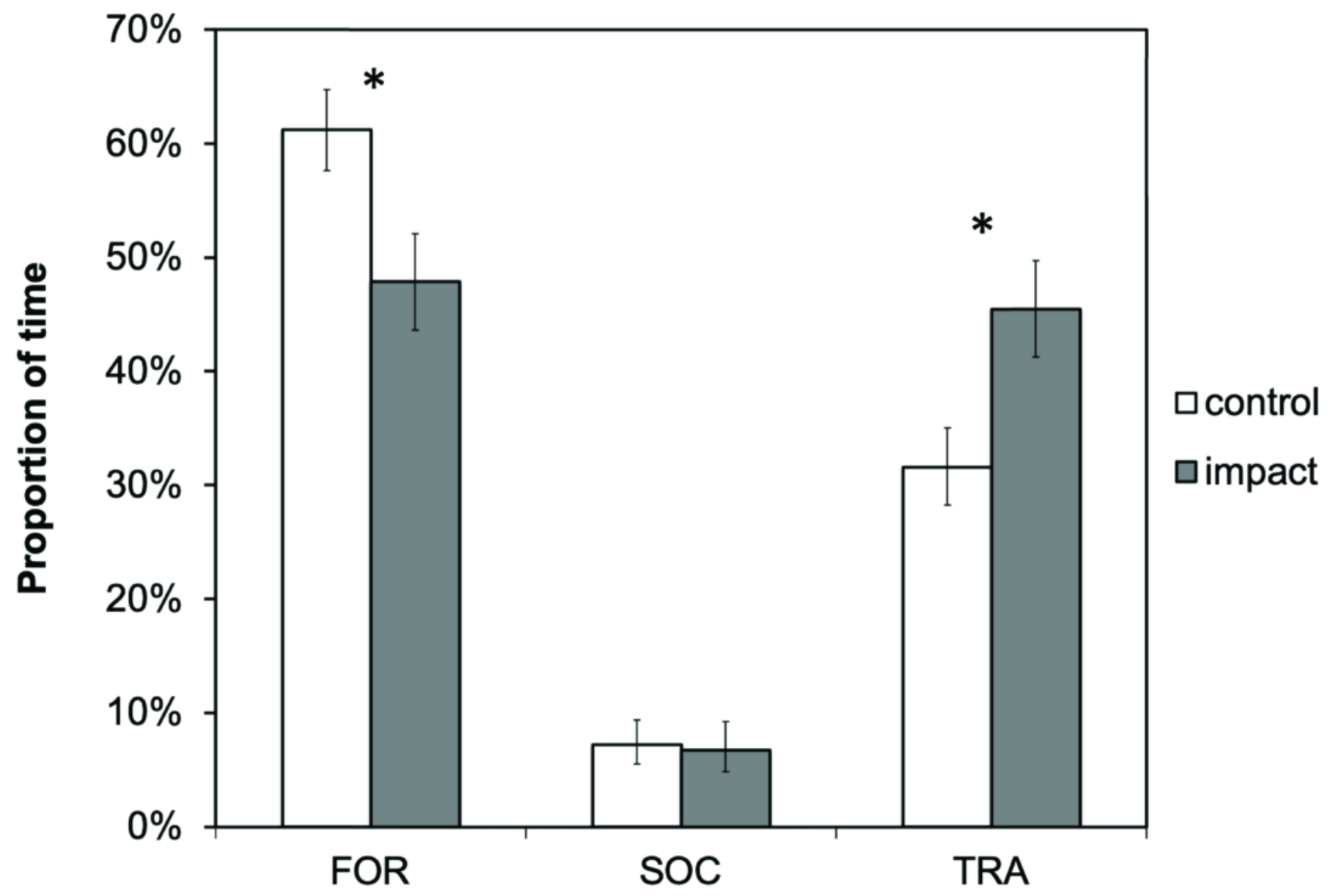

Activity state 
Figure 5

Tour boats impact the activity patterns of bottlenose dolphins (Tursiops truncatus) in Bocas del Toro, Panama Average bout length (min) for each activity state for control (research boat only) and impact (one or more tour boats present) sit

Tour boats impact the activity patterns of bottlenose dolphins (Tursiops truncatus) in Bocas del Toro, Panama Error bars represent the 95\% confidence intervals. Asterisks indicate significant differences $(p<0.05)$.

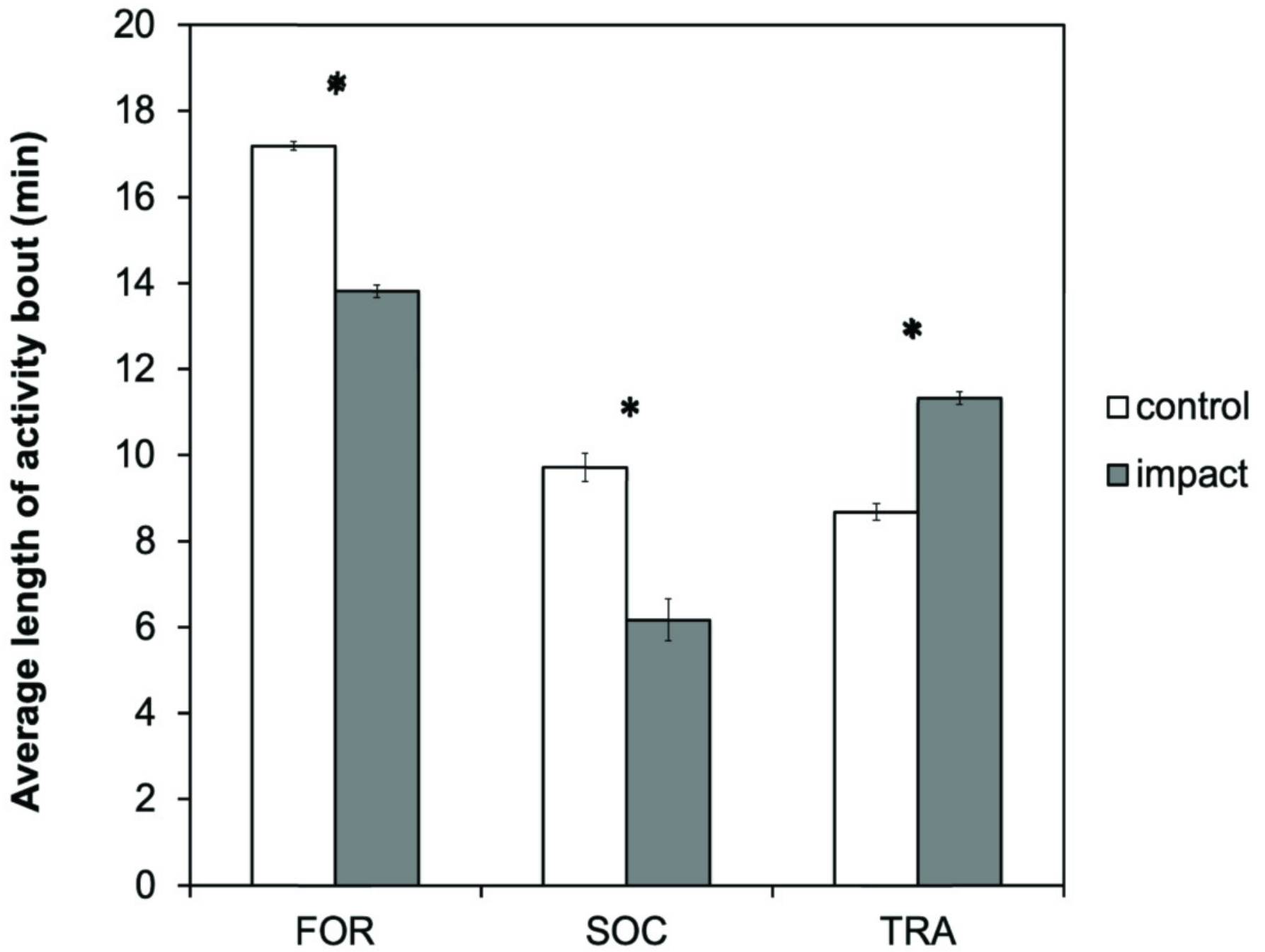

Activity state 


\section{Table $\mathbf{1}$ (on next page)}

Ethogram of activity states for individual bottlenose dolphins recorded during focal animal sampling. 


\section{Table 1:}

2 Ethogram of activity states for individual dolphins recorded during focal animal sampling.

3

\begin{tabular}{|l|l|l|}
\hline $\begin{array}{l}\text { Activity } \\
\text { State }\end{array}$ & Code & Definition \\
\hline Foraging & FOR & $\begin{array}{l}\text { Rapid energetic surfacing, frequent directional changes, fish chases, } \\
\text { observation of individual with fish in their mouths. Peduncle and tail-out } \\
\text { dives frequent (indicating deeper and longer dives). }\end{array}$ \\
\hline Resting & RES & $\begin{array}{l}\text { Low level of individual activity, moving slowly (speed }<2 \text { kts); slow } \\
\text { surfacing 3 to 4 times before diving for an extended period of time. }\end{array}$ \\
\hline Socializing & SOC & $\begin{array}{l}\text { Individual engaged in petting, rubbing, mounting, chasing, genital } \\
\text { inspections, play, displays, and other physical contact with other } \\
\text { individuals. }\end{array}$ \\
\hline Traveling & TRA & $\begin{array}{l}\text { Persistent and directional movement (speed }>2 \text { kts); individual movement } \\
\text { could be meandering but still headed in a general direction. }\end{array}$ \\
\hline
\end{tabular}

4 